\title{
SIMULATION RESEARCH ON CARBON EMISSIONS TRADING BASED ON BLOCKCHAIN
}

\author{
Qing $\mathrm{ZHOU}^{1,2 *}$, Qi ZHANG ${ }^{2}$ \\ ${ }^{1}$ Faculty of Petroleum, China University of Petroleum-Beijing, Karamay, China \\ ${ }^{2}$ School of Economics and Management, China University of Petroleum-Beijing, Changping, China
}

Received 20 August 2020; accepted 05 February 2021

\begin{abstract}
Highlights
Designs a blockchain-based carbon emissions trading simulation model from a macro perspective.

Formulates the behavior rules of agents for the blockchain-based carbon emissions trading process.

Simulates the trading based on public chain and private chain on the Repast platform.
\end{abstract}

\begin{abstract}
Global warming caused by greenhouse gases is one of the problems that need to be solved urgently. Blockchain technology can achieve automatic quota certification and settlement, providing a new direction for carbon emissions trading. This paper provides a quantitative analysis of blockchain-based carbon emissions trading through the Repast simulation platform. Firstly, it designs the blockchain-based carbon emissions trading simulation framework from a macro perspective, including identity and quota certification, quota trading, risk prevention and smart contracts management. Then, it establishes a blockchain-based carbon emissions trading simulation model and formulates the behavior rules of the government, investors and company agents and market transaction processes. Finally, it simulates the carbon emissions trading based on public chain and private chain on the Repast platform, and analyzes the simulation results.
\end{abstract}

Keywords: blockchain, carbon emissions trading, time cost.

\section{Introduction}

Climate change caused by greenhouse gases has become a most important environmental issue in the world. The international community has carried on many discussions about energy conservation and emission reduction issues. To reduce greenhouse gas emissions, the Chinese government has already established carbon emissions trading pilots in seven provinces and launched a nationwide carbon emissions trading market at the end of 2017.

In recent years, with the rise of Bitcoin, blockchain technology has also started as core technology of Bitcoin. The blockchain can solve the problems of high cost, low efficiency, and poor security of third-party organizations and meet the requirements of the energy Internet. Therefore, some scholars began to study the application of blockchain technology in the energy industry to establish the energy Internet. The Brooklyn Microgrid project in the United States uses blockchain technology to develop a trading platform that uses smart meters to capture electricity production and electricity consumption of users, enabling users to trade solar energy with other users ( Fu et al., 2018; Zeng \& Wan, 2010). In China, there is an energy blockchain laboratory that will cooperate with IBM to establish the first blockchain-based carbon asset management platform. In addition, State Grid e-commerce company of China has released a blockchain platform and will develop its application for carbon emissions trading in the future.

Pan et al. (2019) summarized the literature on the application of blockchain in energy trading. In this paper, the blockchain can help communicate directly between the producer and consumer, and apply blockchain for metering, billing and settlement in energy trading, etc.

Al Kawasmi (2015) presented a system-of-systems architecture model based on Bitcoin using Open Transactions for Decentralized Carbon Emissions Trading Infrastructure (D-CETI). In this paper, the evaluation criteria are developed to qualitatively compare the D-CETI

${ }^{*}$ Corresponding author. E-mail: zhouqing@cup.edu.cn 
architecture with five other existing carbon trading systems. In summary, the D-CETI based on Bitcoin will help in the overall reduction of carbon emissions. Fu et al. (2018) proposed a blockchain enhanced ETS solution for the fashion apparel manufacturing industry (FAMI) to reduce the emissions for all the key steps of clothing making. In the paper, a detailed case study is presented. The carbon emissions for FAMI are evaluated from the four aspects supply, energy, labor and wastes.

Alkawasmi et al. (2012) proposed a decentralized carbon emissions trading platform (CarboCoin) which is based on Bit coin in order to reduce carbon emissions. Mengelkamp et al. (2018) presented the concept of a blockchain-based microgrid energy market where consumers and prosumers can keep profits from. Green and Newman (2017) discussed the trends to solar power storage in Perth, Australia and how to use new blockchain support systems for the future power grid. Hu et al. (2014) presented a multi-agent model baesd on complex adaptive system theory in order to simulate the Carbon Emission Trading (CET) Market. Sikorski et al. (2017) explored applications of blockchain technology in the future power market.

Franke et al. (2020) presented an initial proposal for the Paris Agreement carbon market mechanism by applying blockchain technology. To test the feasibility of two blockchain systems, Ethereum and Hyperledger Fabric, a list of technical requirements and soft factors as selection criteria are developed. They concluded that both blockchain systems offer advantages and the adaption of blockchain technology enhances the transparency and efficiency for the Paris Agreement.

Applying blockchain technology to carbon emissions trading can achieve the traceability of transactions and the automation and intelligence of the system. The data can be accessed by all users and without being tampered. Compared with the traditional carbon emission trading model, blockchain-based carbon emissions trading has the following advantages: the automated authentication mechanism, traceability, data openness and transparency, smart contract, etc.

Scholars in the energy field have discussed the application of blockchain technology in carbon emissions trading, but current research mostly focuses on qualitative analysis such as application scenarios. There is a lack of quantitative analysis of blockchain-based carbon emissions trading. In this paper, a blockchainbased carbon emissions trading system on the Repast platform is established and dynamic simulations are conducted. By analyzing the simulation results under different scenarios, the application of blockchain technology in the carbon emissions trading market is studied, which provides a reference for the application of carbon emissions trading.

\section{Blockchain-based carbon emissions trading simulation framework}

This article divides the blockchain into public and private chains in a broad sense. It designs the carbon emissions trading simulation framework based on public and private chains from four aspects: identity and quota certification, quota trading, risk prevention, and smart contract management.

\subsection{Identity and quota authentication}

\subsubsection{Identity authentication}

Blockchain technology can be used for identity authentication in carbon emissions trading. According to the Shanghai Environment and Energy Exchange (Zheng, 2016; Shanghai Environmental Energy Exchange, 2015), users applying for carbon emissions trading need to register an account on the platform. Each account corresponds to a unique node. Each node has a pair of public and private keys. The data encrypted with the node's private key (public key) can only be decrypted with the node's public key (private key). Then they can be used for information encryption and digital signature (Zhu, 2016). The system automatically generates an identity code consisting of user type, public key, and organization code for each node.

The government node in the transaction management system is responsible for reviewing the application data. Only the nodes that have passed the authentication can participate in carbon emissions trading, and the failed nodes will be canceled.

\subsubsection{Quota certification}

Authenticated company nodes can get quotas for free, according to the "National Carbon Emissions Trading Market Construction Plan (Power Generation Industry)" (National Development and Reform Commission, 2017) and "Shanghai Carbon Emission Quota Allocation Plan for 2017" (Shanghai Development and Reform Commission, 2017), the government node uses the industry baseline method to determine the quota allocation plan.

The transaction management system encrypts the quota results sent by the government node, and then issues quotas according to allocation result by the government. For authenticated corporate nodes, the transaction management system creates an input for their wallet address. The amount of input equals the amount of free quota obtained. Finally, the transaction management system creates a new block to record all input and connects it to the blockchain.

On the public chain-based carbon emissions trading platform, the government node creates a new block for the company node based on allocation results. Then the new block is broadcasted to entire network. The entire network authenticates the block created by the government node, the new block will be connected to the blockchain after verification, at which point companies do have the ownership of quotas. 


\subsection{Quota trading}

\subsubsection{Transfer quotas}

In the quota transaction, the transfer of ownership uses the transaction order as a carrier (Nakamoto, 2008), its operating mechanism is shown in Figure 1. The seller uses its UTXO as an input, the quota transferring to the buyer and its wallet address as outputs to create a transaction order, and then hash the input and buyer's public key to get a hash value. Finally, the signature is encrypted with its private key and appended to the end of the quota.

When trading on private chain-based carbon emissions trading platform, nodes need to submit orders to the transaction management system. After completing the order matching, the buyer and the seller will create a transaction order for quota trading. At last, the transaction management system records all transactions into a new block and connects it to the blockchain.

On the public chain-based carbon emissions trading platform, traders conduct P2P transactions. The node that obtains the recording rights records the transaction in a new block, the new block will be connected to the blockchain after verification.

\subsubsection{Record book}

In blockchain-based carbon emissions trading, all transactions are recorded in the block. Block head contains the previous block address, hash value, merkle root, and timestamp, block body contains all transaction records over a period of time. Merkle root is calculated from the transactions in the block body. Each transaction generates a hash value by hash operation, the two adjacent hash values are hashed to get a new hash value, and finally the value of merkle root is obtained (Xie \& Wang, 2016).

On the private chain-based carbon emissions trading platform, the transaction management system records the book, and within a certain time period, the transactions generated is recorded in a new block. Due to the credibility of the transaction management system, this block will connect to the blockchain without being verified by the entire network node.

On the public chain-based carbon emissions trading platform, each node has the right to record the book. To save power, the bookkeeping right is randomly distributed among nodes. When a new block is created, it needs to be broadcasted to the entire network for verification, the verification process is based on the Tendermint protocol mechanism (Ilic et al., 2012).

\subsection{Risk prevention}

\subsubsection{Monopoly risk}

According to the Shanghai Environment and Energy Exchange, the monopoly risk is prevented by setting quota limits (Shanghai Environmental Energy Exchange, 2015). The number of quotas held by each node cannot be greater than the maximum amount of government regulations. The company's maximum holding quantity comes from the free quota obtained at the beginning of the year. Then the maximum holding of investors is a fixed value. In quota trading, the sum of the quota holding amount and purchase amount of the node cannot exceed the maximum holding amount. If the holding amount reaches the specified upper limit, the node can no longer purchase quota (Wu, 2014).

\subsubsection{Payment risk}

On the private chain-based carbon emissions trading platform, to prevent payment risks, quotas in transaction are managed by the transaction management system. The public chain-based carbon emissions trading platform circumvents payment risks by setting up an escrow node. The role of the escrow node is the same as that of the transaction management system on private chain-based carbon emissions trading platform. But it needs to sign the order with private key and broadcast it to the entire network when a seller receives payment from a buyer. Only after the entire network passes the verification, can the escrow node release the frozen quota.

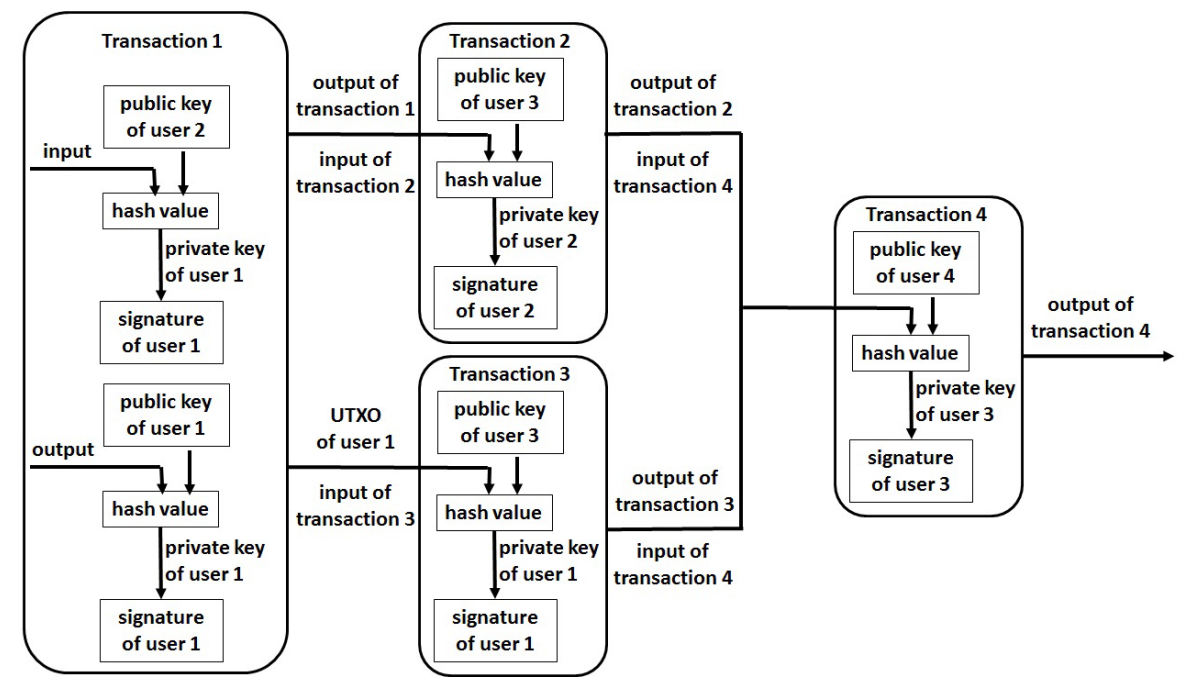

Figure 1. Trading mechanism 


\subsubsection{Credit risk}

By applying blockchain technology to carbon emissions trading and formulating corresponding rules, it is possible to ensure the integrity of transactions between trading parties and avoid credit risks. The rules are as follows: Firstly, when an enterprise or organization registers an account, the corresponding identity code will be generated and recorded in the blockchain which is available for review at any time. Secondly, all transaction records are stored in the form of distributed ledgers, and each transaction related to the trading quota can be traced back by each node to ensure the validity of the quota. Thirdly, the better the credit status of the node is, the higher the credit score, and the credit level of the node can be known through the credit score.

\subsection{Smart contract management}

A smart contract is an automatically executable agreement that specifies the responsibilities and obligations of the parties to the contract and the conditions for determining whether the contract is executed. The system determines whether the conditions are met by updating the status of both sides of the contract in real-time. If the conditions are met, the contract clause will be automatically enforced (Lu et al., 2017). It can be used to impose fines on companied with excess emissions and to update the credit score of a node.

\subsubsection{Fine}

All companies need to sign a smart contract that can be automatically fined on the blockchain-based carbon emissions trading platform. Stranlund (2007) discussed the relationship between marginal penalty and carbon emission reduction.

The status of smart contracts is related to the actual emissions and the quota clearance amount of the company node. When clearing the quotas at the end of the year, if the actual emissions of the company do not exceed the quota clearance amount, the smart contract will remain untriggered, otherwise, it will be triggered. If the smart contract is in a triggered state, the system will automatically read and execute the relevant code and fine the company. After executing the smart contract, the execution result will be returned to the blockchain through the corresponding interface, the mechanism is shown in Figure 2.

\subsubsection{Update credit score}

Each user needs to sign a smart contract to update the credit score when registering. The process of contract release is the same as that of the smart contract with an automatic penalty.

\section{Blockchain-based carbon emissions trading simulation model}

\subsection{Basic assumptions}

- The trading agent only trades quotas on the market but does not generate new quotas.

- Trading agents are all aiming at maximizing profits.

- Price is updated in units of one time step.

- Quota price is formed by the market mechanism.

- Each agent only has a unique account, and corresponding to one node.

- Ignoring the time spent on upgrading emission reduction technologies, carbon emissions reduce in the current period after technological improvements.

\subsection{Agent behavior rules}

\subsubsection{Government agent}

Industry benchmark method is used when issuing quotas, the free quota quantity of the company, $F Q_{i}$ is calculated using the following formula:

$$
F Q_{i}=S \times \eta \times X_{i}
$$

where: $S$ is the carbon emission standard per unit of integrated power supply, $\eta$ is the comprehensive correction factor, $X_{i}$ is the annual comprehensive power generation of the company. The corresponding $S$ and $\eta$ for different fuels are shown in Table 1.

Table 1. Coefficients for different fuels

\begin{tabular}{|c|c|c|}
\hline Type & $S$ (tons of $\mathrm{CO}_{2} /$ Million $\mathrm{kWh}$ ) & $\eta$ \\
\hline Gas & 4.281 & 1 \\
\hline Oil & 8.103 & 1 \\
\hline Coal & 8.829 & 1.02 \\
\hline
\end{tabular}

The government agent needs to impose fines on companies with excessive emissions. Refering to $\mathrm{Hu}$ Dongbin's

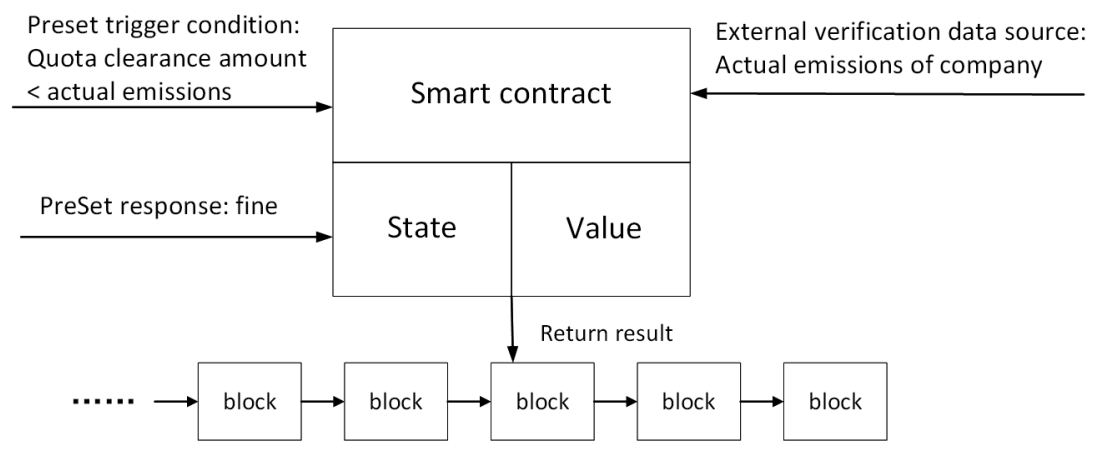

Figure 2. Execution mechanism of smart contract 
setting of fines (Hu et al., 2014), the fine for a company $P n_{i}$ is calculated by multiplying the excess emissions by the penalty benchmark $u, E_{i}$ is the actual emissions of the $i$-th company, $Q_{i}$ is the quota clearance amount of $i$-th company on the clearing date.

$$
P n_{i}=u \times\left(E_{i}-Q_{i}\right) \text {. }
$$

The government agent also needs to grant technical subsidies to companies that improve their technology. The amount of subsidy Tech $_{i}$ will be determined by the technical improvement cost of company $T C_{i}$, and $\mathrm{m}$ is the rate of technical subsidies determined by the government. According to Wu Jiaqian's study (Wu, 2015), system efficiency is higher when $m$ is taken at $10 \%$.

$$
\mathrm{Tech}_{i}=m \times T C_{i} .
$$

\subsubsection{Investor agent}

The investor agent must firstly determine its expected price $E P_{i, t}$ based on last period market price $P_{t-1}$. The formula is shown below, $\varepsilon$ is the coefficient of variation of investor's expected price.

$$
E P_{i, t}=P_{t-1} \times \varepsilon .
$$

If the expected price is higher than the market price of last period, the investor agent will purchase quota. If the expected price is lower than the market price of last period, the investor agent will sell quota. When the two are equal, the investor agent chooses to wait for the next transaction. If the investor agent chooses to trade, it also needs to determine the quotation and trading volume.

The quotation $Q P_{i, t}$ is determined by the last previous market price, the expected price and the amount of fundholding, the calculation formula is as follows:

$$
Q P_{i, t}=\left[r \times P_{t-1}+(1-r) \times E P_{i, t}\right] \times \omega,
$$

where: $r$ is the weighting coefficient based on the market price of the previous period, it is determined by the amount of funds $C_{i, t}$, which is held by investors in the current period. The corresponding rules for $r$ and $C_{i, t}$ are shown in Table 2. $\omega$ is the quotation adjustment coefficient, the investor agent adjusts the quotation according to market conditions, the rules for the value of $\omega$ are shown in Table 3.

Table 2. Investor agent's hold funds and weight coefficient

\begin{tabular}{|c|c|}
\hline$C_{i, t}$ (Ten thousand yuan) & $r$ \\
\hline$C_{i, t}>90$ & 0.1 \\
\hline $90 \geq C_{i, t}>70$ & 0.2 \\
\hline $70 \geq C_{i, t}>50$ & 0.4 \\
\hline $50 \geq C_{i, t}>30$ & 0.6 \\
\hline $30 \geq C_{i, t}>10$ & 0.8 \\
\hline $10 \geq C_{i, t}$ & 0.9 \\
\hline
\end{tabular}

Table 3. Quote adjustment coefficient

\begin{tabular}{|l|c|c|c|c|}
\hline $\begin{array}{l}\text { Lust period } \\
\text { period }\end{array}$ & $\begin{array}{c}\text { Successful } \\
\text { purchase }\end{array}$ & $\begin{array}{c}\text { Successful } \\
\text { sale }\end{array}$ & $\begin{array}{c}\text { Failed } \\
\text { purchase }\end{array}$ & $\begin{array}{c}\text { Failed } \\
\text { sale }\end{array}$ \\
\hline Purchase & 0.8 & 1.0 & 1.2 & 1.0 \\
\hline Sale & 1.0 & 1.2 & 1.0 & 0.8 \\
\hline
\end{tabular}

The trading volume is determined by the quotation and the market price of last period. When the difference between the quotation and last period market price is small, investor agent will increase the trading volume. When the difference is large, the investor agent will be cautious in trading. This article uses the price difference coefficient Re to express the degree of differences between the market price in last period and quotation, the formula is as follows:

$$
\operatorname{Re}=\left|\left(Q P_{i, t}-P_{t-1}\right) / Q P_{i, t}\right| .
$$

When the investor chooses to purchase quotas, the amount of invested funds is the product of the fund holdings and the invest ratio coefficient $\beta$, the correspondence between the value of $\beta$ and the price difference coefficient Re is shown in Table 4. When purchasing quotas, the investor must also ensure that the sum of the current quota holdings $Q_{i, t}$ and the trading volume does not exceed the limit $\mathrm{M}$. The calculation formula for the trading volume $A_{i, t}$ is as follows:

$$
A_{i, t}=\min \left[\frac{C_{i, t} \times \beta}{Q P_{i, t}}, M-Q_{i, t}\right] .
$$

Table 4. Investment ratio coefficient and price difference coefficient

\begin{tabular}{|c|c|}
\hline $\operatorname{Re}$ & $\beta$ \\
\hline $\operatorname{Re}>0.1$ & 0.3 \\
\hline $0.1 \geq \operatorname{Re}>0.08$ & 0.4 \\
\hline $0.08 \geq \operatorname{Re}>0.06$ & 0.5 \\
\hline $0.06 \geq \operatorname{Re}>0.04$ & 0.6 \\
\hline $0.04 \geq \operatorname{Re}>0.02$ & 0.7 \\
\hline $0.02 \geq \operatorname{Re}$ & 0.8 \\
\hline
\end{tabular}

When the investor chooses to sell quotas, the number of transactions is the product of the current quota holding amount $Q_{i, t}$ and the invest ratio coefficient $\beta$, the formula is as follows:

$$
A_{i, t}=Q_{i, t} \times \beta .
$$

The investor's credit score Cred $_{i, t}$ is the evaluation index of investor agent's credit level in the $t$-th period, agent with higher credit can trade preferentially if the quotationis the same. The credit score is related to the number of transactions TxAmount ${ }_{i, t}$ and the number of violations DAmount $_{i, t}$. 


$$
\text { Cred }_{i, t}=\left(1-\frac{\text { DAmount }_{i, t}}{\text { TxAmount }_{i, t}}\right) \times 10 .
$$

\subsubsection{Company agent}

The emission-controlling company agent estimates the annual emission $E_{i}$ at the beginning of each year. The formula is as follows, where $\theta$ is the actual emission coefficient which is a random number within a certain range, the setting of the range is shown in Table 5.

$$
E_{i}=X_{i} \times \theta .
$$

Company agent determines its expected price $E P_{i, t}$ based on the last period market price $P_{t-1}, \varepsilon$ is the coefficient of expected price's variation.

$$
E P_{i, t}=P_{t-1} \times \varepsilon .
$$

According to the study of Kong Chuiyao (Kong, 2012), the marginal abatement cost $M A C_{i, t}$ of company is linearly related to cumulative reductions $N_{i, t}$, which is equal to the product of cumulative reductions and the marginal emission reduction coefficient $k$. The calculation formula of $M A C_{i, t}$ is as follows, where $\mathrm{m}$ is the government's technical subsidy ratio. Because of the different technical levels of companies, $k$ takes a random number from 0 to 400 .

$$
M A C_{i, t}=k \times(1-m) \times N_{i, t} .
$$

The cumulative emission reductions of company from the beginning of the transaction to the beginning of pe$\operatorname{riod} \mathrm{t}$ is $N_{i, t}$ the emission reductions in the $t$-th period is $n_{i, t}$ and the technical emission reduction cost $T C_{i, t}$ in the $t$-th period is calculated as follows (Kong, 2012):

$$
T C_{i, t}=\int_{0}^{N_{i, t}+n_{i, t}} M A C_{i, t} d q-\int_{0}^{N_{i, t}} M A C_{i, t} d q .
$$

The difference between the amount of actual emissions and quotas held by the company during the $t$-th period is $T E_{i, t}$ the decision process of company agent is shown in Figure 3. The penalty amount $P n_{i, t}$ is the product of the government's penalty benchmark $u$ and $T E_{i, t}$, and MinCost ${ }_{i, t}$ is the optimal function of technical improvement and purchase quota's combination, the calculation formula is as follows:

$$
\begin{aligned}
& T E_{i, t}=E_{i, t}-Q_{i, t} ; \\
& \text { MinCost }=\min \left[T C_{i, t}+E P_{i, t} \times\left(T E_{i, t}-n_{i, t}\right)\right] .
\end{aligned}
$$

To obtain greater profits, company agent adjusts the quotation based on the expected price. The calculation formula for the buying and selling quotation are as follows, where $\lambda$ is a random number between 0 and $0.2, \omega$ is the quotation adjustment coefficient whose value rules are as the same as that of the investor agent.

$$
\begin{aligned}
& \text { Buy: } Q P_{i, t}=E P_{i, t} \times(1-\lambda) \times \omega ; \\
& \text { Sale: } \quad Q P_{i, t}=E P_{i, t} \times(1+\lambda) \times \omega .
\end{aligned}
$$

The trading volume of the company agent is determined by quotations and market price of last period. The calculation method of the company agent price difference coefficient Re and the corresponding investment ratio $\beta$ are the same as that of the investor agent. According to $\mathrm{Xu}$ Mei's research (Xu \& Tang, 2014), to prevent all companies from conducting transactions in the prior period, it is necessary to limit the trading volume in each period to a maximum value of MAX. In addition, to prevent companies from monopolizing the market, every company has a maximum quota holding $M a x Q_{i}$.

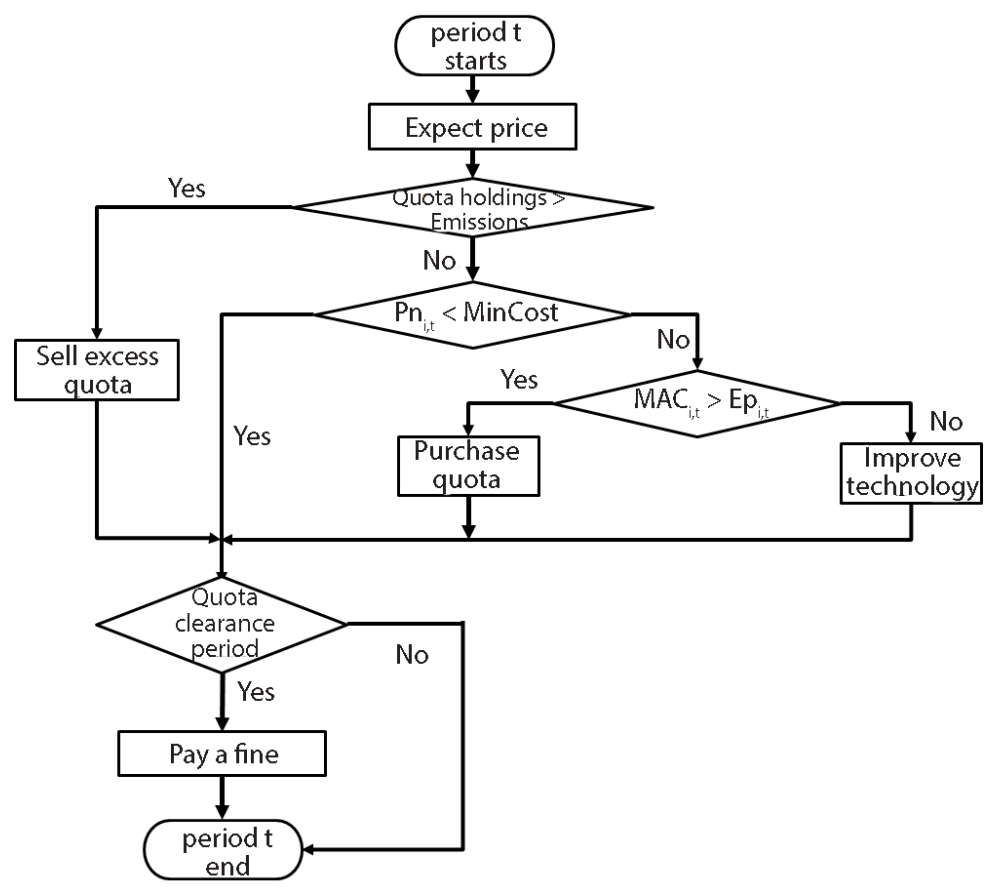

Figure 3. Decision flow chart 
When companies choose to sell quotas, if no technical improvements are made, the calculation formula for trading volume $A_{i, t}$ is as follows:

$$
A_{i, t}=\min \left[T E_{i, t} \times \beta, M A X\right] .
$$

If the excess quota is sold through technical improvements, the formula for calculating the trading volume $A_{i, t}$ is as follows:

$$
A_{i, t}=\min \left[S Q_{i, t} \times \beta, M A X\right] .
$$

When the company agent chooses to purchase quotas, the calculation formula for the trading volume $A_{i, t}$ is as follows:

$$
\begin{aligned}
& \operatorname{Max}_{i}=F Q_{i} \times 10 ; \\
& A_{i, t}=\min \left[B Q_{i, t} \times \beta, \operatorname{Max} Q_{i}-Q_{i, t}, M A X\right] .
\end{aligned}
$$

The company agent's credit scoreCredi, $t$ is calculated in the same way as the investor agent.

\subsection{Blockchain-based carbon emissions trading process}

\subsubsection{Carbon emissions trading process based on private chain}

The process of private chain-based carbon emissions trading is shown in Figure 4. The government determines the quota allocation plan, the penalty benchmark, and the technology subsidy ratio according to the market conditions, and then distributes the free quota to companies. Companies and investors make decisions based on their circumstances and expectations. In the quota clearance period, smart contracts will automatically impose fines on companies with excess emissions. Then the government will subsidize companies that improve the technology. When agents want to trade, they must submit an order to the transaction management system. The transaction management system performs transaction matching and records all transactions in a new block, and finally, it connects the new block to the blockchain and broadcasts to the entire network.

The transaction management system firstly divides all orders into two types: buying and selling. Then according to the principle of price, time, and credit priority, the transaction is matched. The price adjustment is related to the total transaction amount reported by unfilled purchase orders $\left(Y_{1}\right)$ and the total transaction amount reported by unsold sales orders $\left(Y_{2}\right)$. The formula is as follows, $r_{1}$ is a random number between 0 and 1 .

$$
\begin{aligned}
& Y_{1}<Y_{2}: \quad Q P_{i, t}^{\prime}=Q P_{i, t} \times\left(1-r_{1} \times \frac{Y_{2}-Y_{1}}{Y_{2}}\right) ; \\
& Y_{1}>Y_{2}: \quad Q P_{i, t}^{\prime}=Q P_{i, t} \times\left(1+r_{1} \times \frac{Y_{1}-Y_{2}}{Y_{1}}\right) .
\end{aligned}
$$

After completing transactions of a period, the transaction management system calculates all transactions to

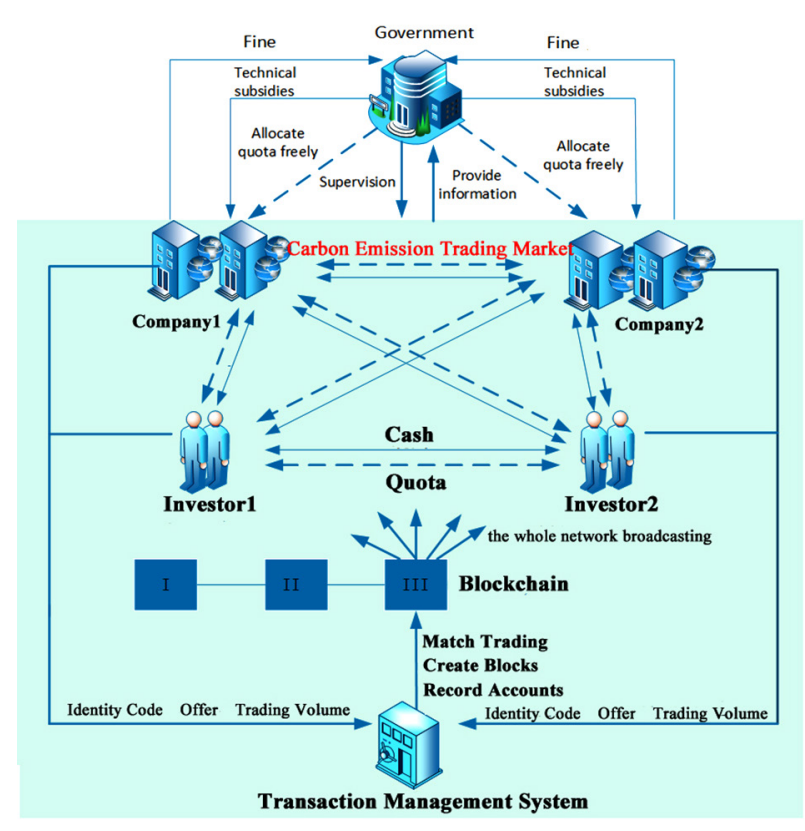

Figure 4. Transaction flow chart based on private chain

obtain the current market price as well as trading volume and issuing a closing signal. The market price is calculated as follows, $p_{i, t}$ is the deal price of each transaction, $a_{i, t}$ is the transaction volume.

$$
P_{t}=\frac{\sum_{i=1}^{i=n} p_{i, t} \times a_{i, t}}{\sum_{i=1}^{i=n} a_{i, t}} .
$$

\subsubsection{Carbon emissions trading process based on public chain}

The process of public chain-based carbon emissions trading is shown in Figure 5, where P2P transactions are conducted between agents. The node which decides to trade quotas needs to send transaction information to the entire network. The node selling the quotas will choose the node with the highest quotation among the received purchase information, while the node buying quotas will choose the node with the lowest quotation to conduct the transaction. If in the same case, the node with the highest credit score will be selected first. After confirming the transaction, the node will send the transaction information to the entire network. The node with the accounting rights writes all transaction information in a new block and broadcast this block to the entire network. Each node verifies the new block, which will be connected to the blockchain after passing the verification.

Nodes that fail to make a transaction will adjust the quotation and send the transaction information to the entire network again. The adjustment rules for buyers and sellers are as follows, where $r_{2}$ is a random number between 0 and 1 . The market price is calculated in the same way as the private chain. 


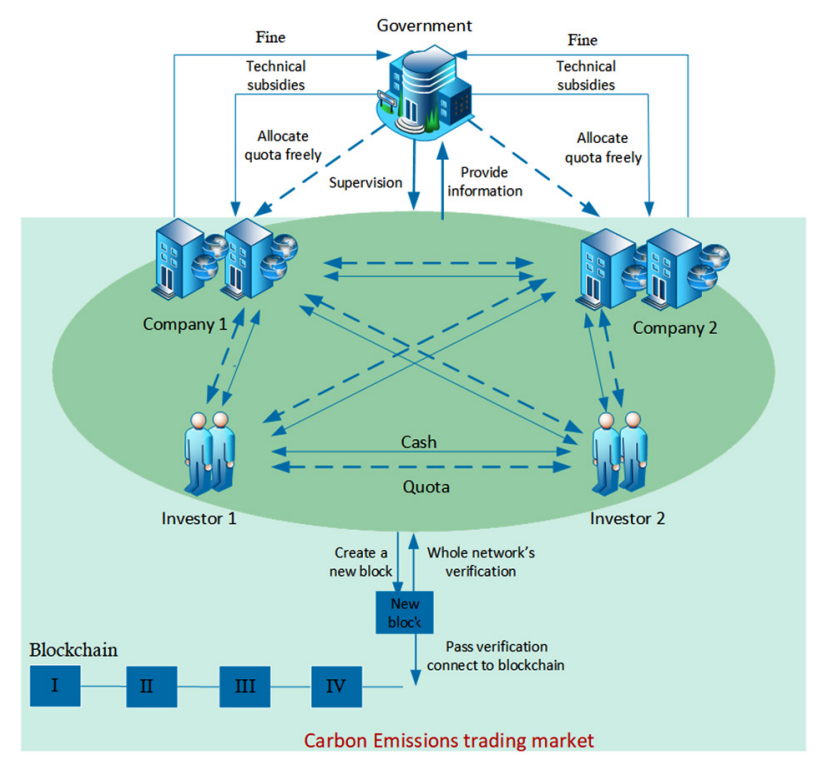

Figure 5. Transaction flow chart based on private chain

$$
\begin{aligned}
& Q P_{i, t}^{\prime}=Q P_{i, t}-r_{2} \times\left|P_{t-1}-Q P_{i, t}\right| ; \\
& Q P_{i, t}^{\prime}=Q P_{i, t}+r_{2} \times\left|P_{t-1}-Q P_{i, t}\right| .
\end{aligned}
$$

\section{Simulation system's operation and analysis}

\subsection{Initial parameter settings}

According to the recent quota price of Shanghai carbon emissions trading market, the market price in the initial state of the simulation is set at RMB 34.00/ton, one iteration step represents one day, a period transaction is conducted and a new block is created every day, and there are 332 days for trading in a year.

The agents in the simulation are divided into three categories: the government, investors and companies. At the beginning of the simulation, the default number for each agent is 0 .

The number of the government agent is 1 , the technical subsidies rate of government is set at $10 \%$, and the penalty benchmark $u$ is set at 102 yuan/ton.

The number of investors is 50 . In the initial state, the investor quota holding is zero, the amount of fund holdings is 1 million yuan, and the maximum of quota $M$ is 100,000 tons.

The companies selected from the power industry are divided into three categories according to the different types of fuel, each category has 50 agents, and a funds holding of 5 million yuan. The actual emission factor of the company and the annual comprehensive power supply are set in Table 5 .

\subsection{Analysis of simulation results}

Simulation running interfaces of blockchain-based carbon emissions trading are as follows, the majority of yellow agents indicate that most agents are in a waiting state. In
Table 5. Parameter settings of company agent

\begin{tabular}{|l|c|c|}
\hline $\begin{array}{c}\text { Fuel } \\
\text { type }\end{array}$ & $\begin{array}{c}\text { Annual comprehensive } \\
\text { power supply }(10 \mathrm{Kw})\end{array}$ & $\begin{array}{c}\text { Emission factor (tons } \\
\left.\text { of } \mathrm{CO}_{2} / \text { million } \mathrm{kWh}\right)\end{array}$ \\
\hline Gas & 7000 & $3.8 \sim 4.9$ \\
\hline Oil & 4000 & $7.0 \sim 8.3$ \\
\hline Coal & 3500 & $7.8 \sim 11.8$ \\
\hline
\end{tabular}

addition, blue agents are more than green agents, indicating that there are more agents choosing to purchase quotas in the market. The Simulation running interface is shown in Figure 6.

The simulation offers dynamic changes in multiple indicators, which is conducive to the analysis of carbon emissions trading. These multiple indicators include market price, quota purchase amount and emission reductions ofcompany agents, cumulative reductions, the number of companies with improved technology, the number of active nodes, the credit score of agents, the time cost of carbon emissions trading, and so on.

In blockchain-based carbon emissions trading, themarket price of quota shows an upward trend (Figures 7, 8). At the beginning of the transaction, investors enter the market, companies with high marginal abatement costs purchase quotas. There is a large demand for quotas in the market, thus market prices rise faster. In the later stages of the transaction, the difference between supply and demand is small, and the rate of price growth slows.

The amout of quota purchase and emission reductions at each run are shown in Figure 9 and Figure 10. Blue represents the amount of quota purchase, red represents emission reductions of the company agent due to improved technology. With iterations going on, the amount of quota purchase amount and emission reductions show a downward trend. As companies began to perform quota trading and technological improvements at the beginning of the transaction, the demand for quotas continues to be met, thus the purchase of quotas continues to decrease. With the continuous increase of marginal abatement costs, emission reductions by companies have also gradually decreased. In addition, due to the limitation of the technical

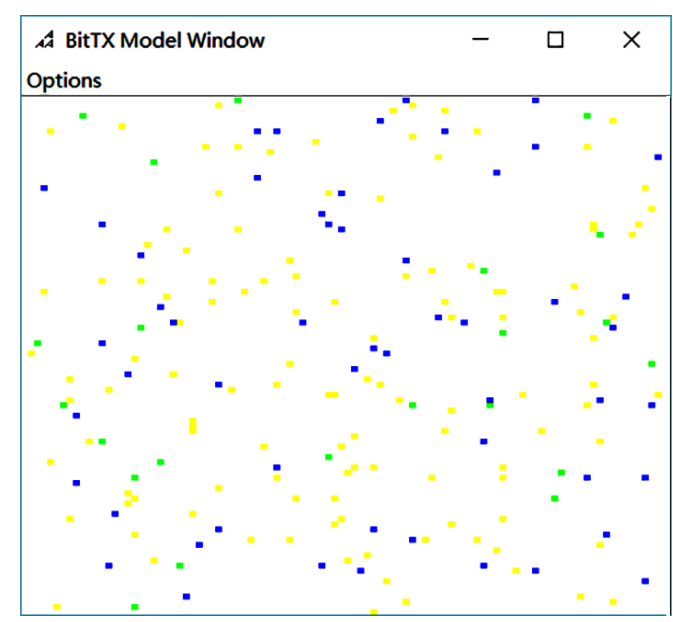

Figure 6. Running interface 
level, the volume of quotas is always greater than the amount of emission reductions, indicating that companies are more inclined to complete emission reduction tasks by purchasing quotas.

The cumulative emission reductions resulting from the improvement of technologies by companies are shown below. Red represents total cumulative emission reductions, green represents the cumulative emission reductions of gas-fired power generation companies, blue represents cumulative reductions from fuel-fired power generation companies, black represents cumulative emission reductions from coal-fired companies. From the figure, at the beginning of the transaction the quota demand is large and the marginal cost of technological improvement is low, so the companies are continuously making technical improvements, and the accumulative emission reduction rate is growing rapidly.

The simulation result displays that as the demand for quotas of companies is continuously being met and the marginal cost of technological improvements is increasing, the number of control companies choosing to improve their technologies gradually decreases. The cumulative emission reduction curve shows a flat trend. In addition, the cumulative emission reductions show an overall rising trend. It indicates that carbon emissions trading can effectively promote the control companies to improve technology, thereby reducing carbon emissions.

In this paper, the time cost is defined as the time difference between transaction creation and transaction entry into the blockchain. The time cost of private chainbased carbon emissions trading chain shows an overall growth trend with iterations (Figure 11). The growth rate of time cost is faster from 0 to 140 steps. After 140 steps, the time cost stabilizes and fluctuates in the range of 0.45 to 0.65 milliseconds. In the public chain-based carbon emissions trading based (Figure 12), in the first 200 steps, the number of iterative steps has a greater impact on time cost whose growth rate is faster. While the growth rate of time cost is relatively slow after 200 steps, changes in the number of iterative steps have little effect on the time cost. The time cost of public chain-based carbon emissions trading is also related to the number of verification nodes the more verification nodes, the higher the time cost of transactions.

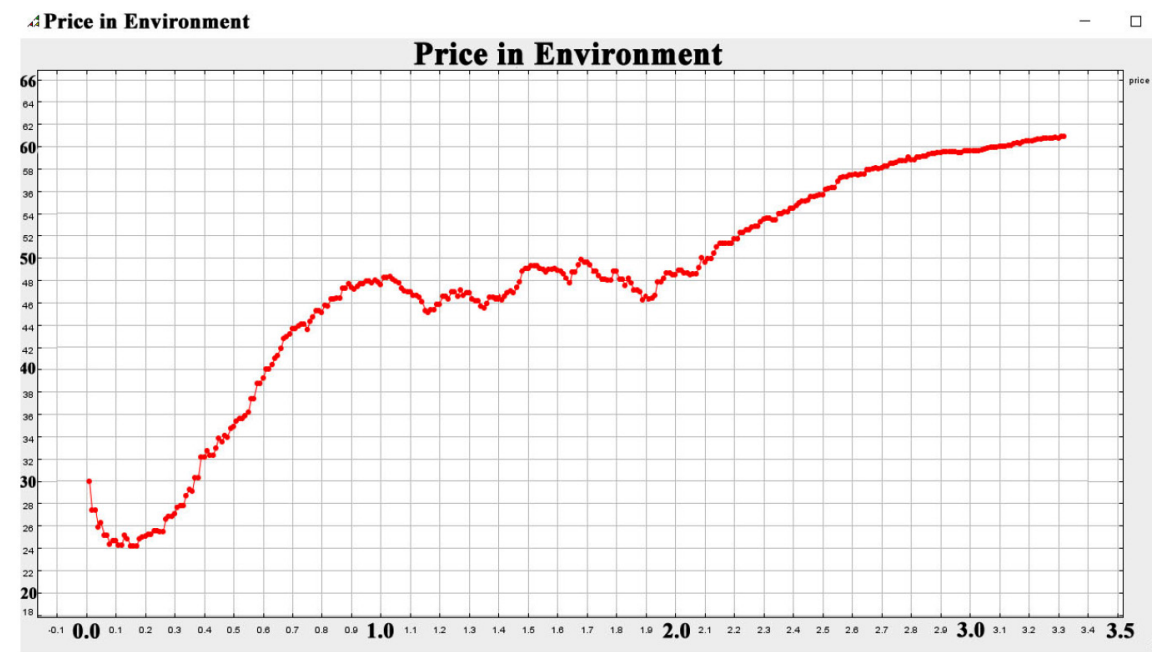

Figure 7. Market price curve - private chain

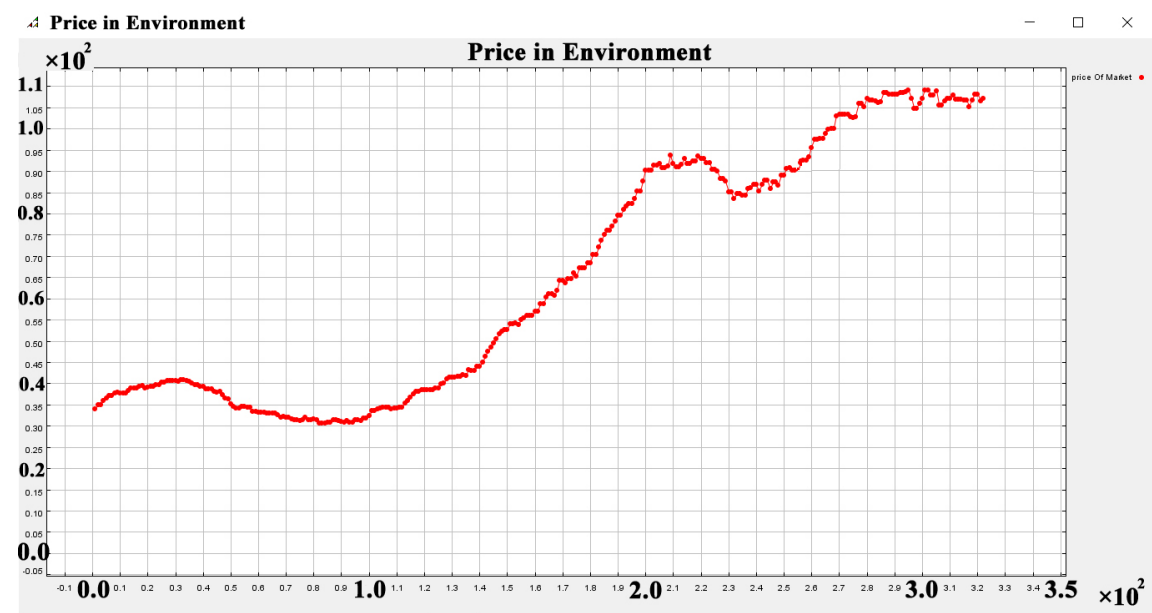

Figure 8. Market price curve - public chain 


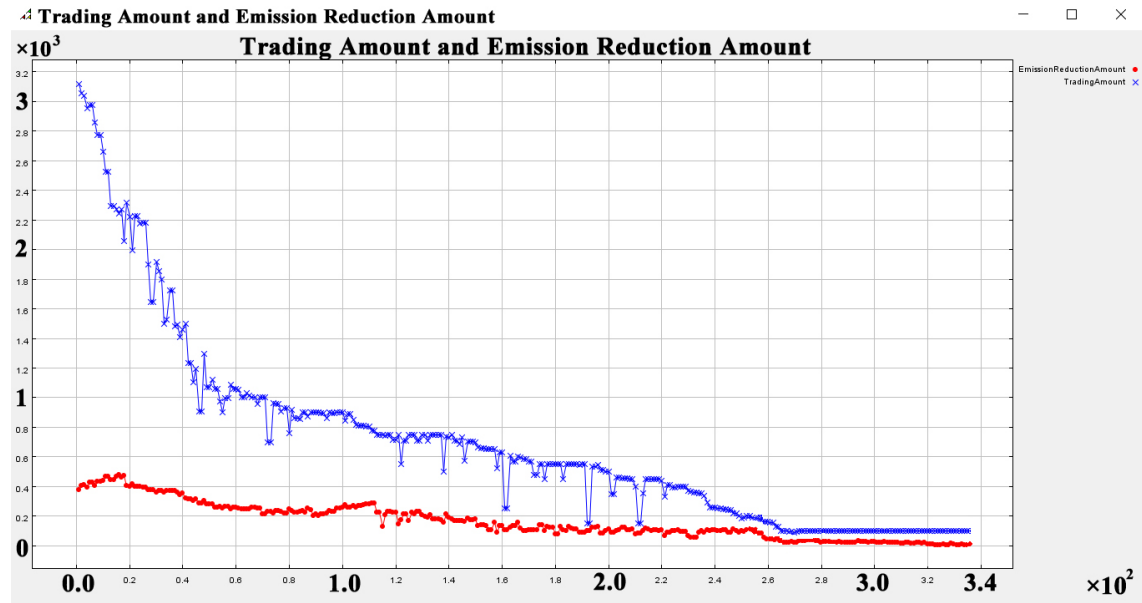

Figure 9. Quota purchase amount and emission reduction curve by step - private chain

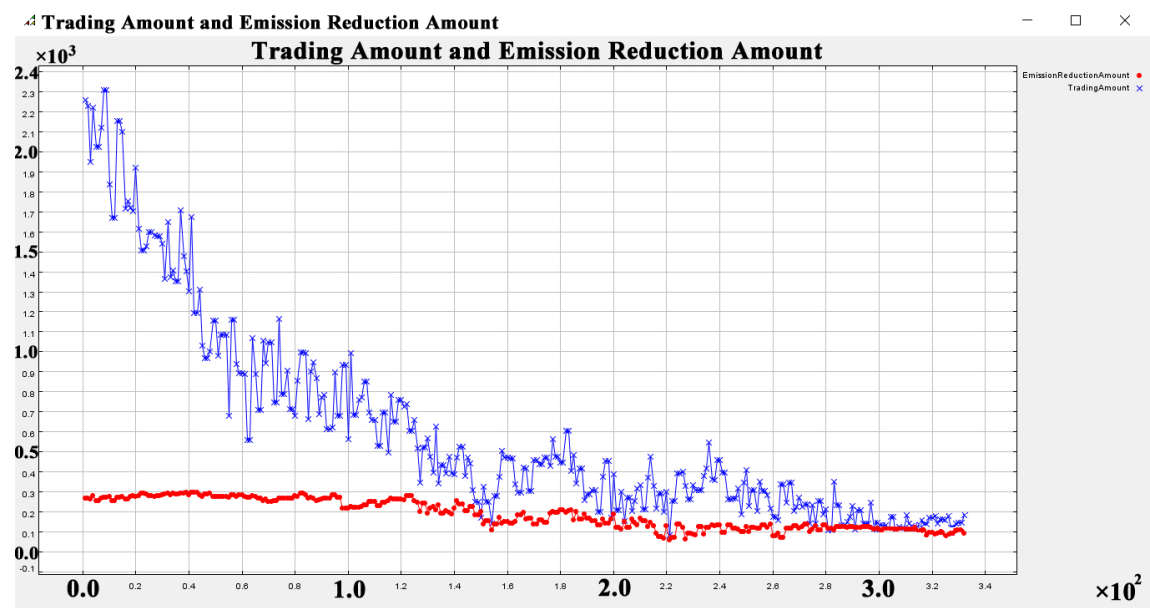

Figure 10. Quota purchase amount and emission reduction curve by step - public chain

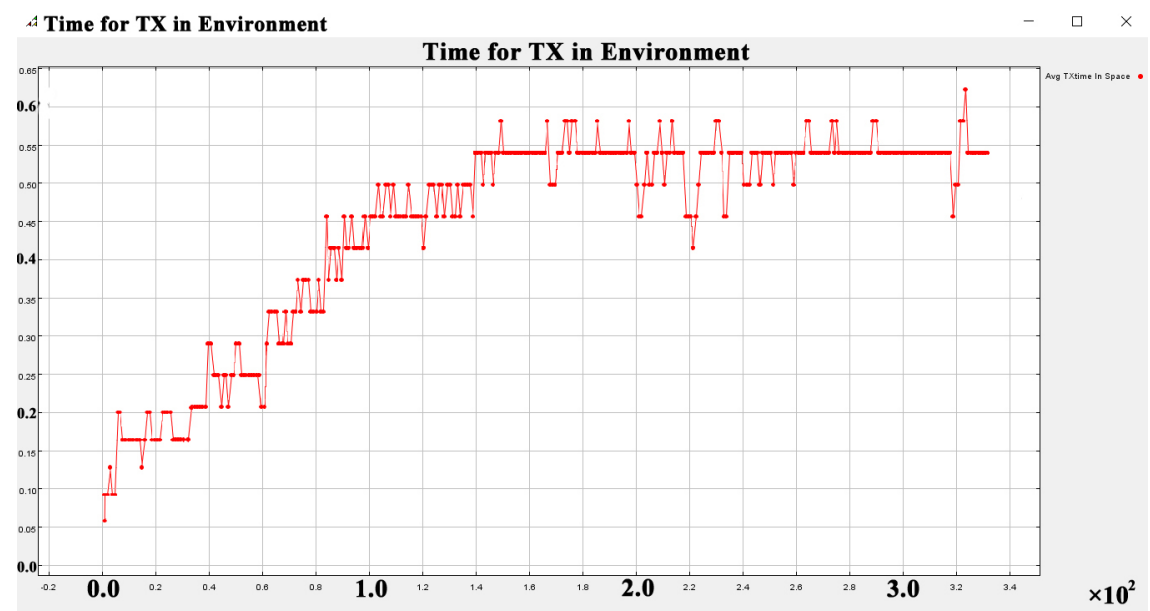

Figure 11. Time cost curve - private chain 


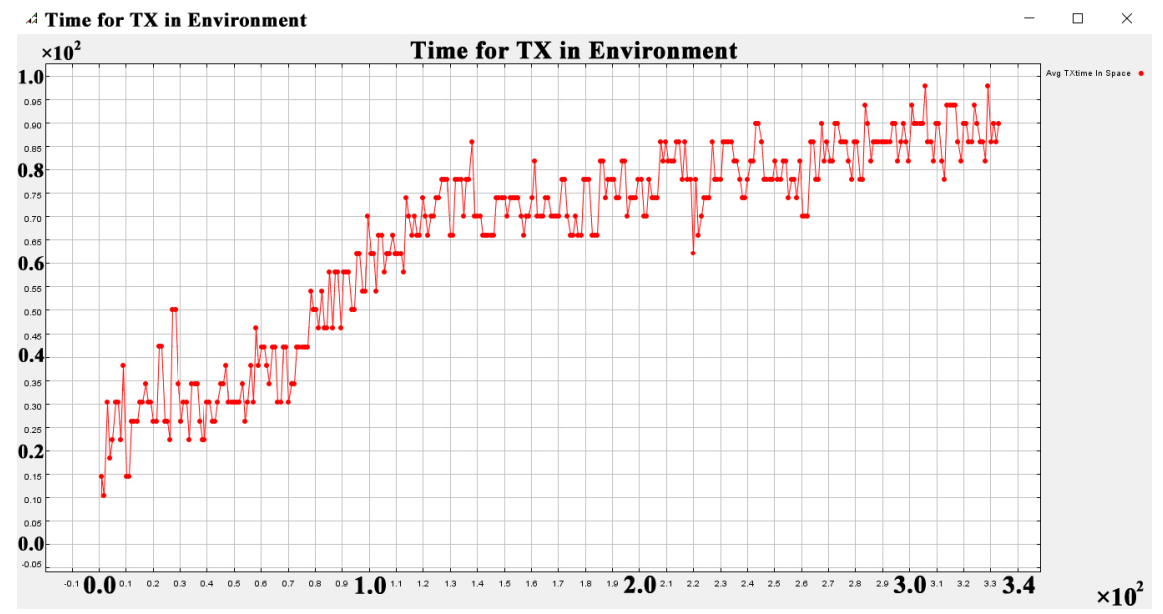

Figure 12. Time cost curve - public chain (200 verification nodes)

\section{Conclusions}

Climate change has become a global issue, how to reduce greenhouse gas emissions is a hot topic in academic research. Blockchain technology provides a new direction for the research of carbon emissions trading, which can realize the automation and intelligence of quota certification and payment, and reduce transaction costs. In this paper, by combining blockchain technology with carbon emissions trading, a simulation study of carbon emissions trading based on different types of blockchains is carried out. The simulation results show that carbon emission trading can promote technology upgrades of emission control companies and reduce carbon emissions. Blockchain technology can solve the problem of a large amount of quota certification and traceability, and reduce the transaction costs. These should provide technical support for the nationwide carbon emissions trading.

The nationwide carbon emissions trading platform has a large number of users and requires a high transaction speed. By analyzing the simulation results, it is known that the time cost of private chain-based carbon emissions trading is lower than public chain-based. The public chain-based carbon emissions trading system requires a lot of time for network-wide certification. While the private chain-based carbon emissions trading system can only be recorded in the blockchain through the verification of the transaction management system. Then, in the early stages of carbon emissions trading, private chains are more suitable for carbon emissions trading system in China.

At present, the application of blockchain technology in carbon emissions trading needs further research. Based on existing research results, this paper carries out a preliminary exploration of the blockchain-based carbon emissions trading, and simplifies the behavioral rules of agents when building the simulation model. This will need to be improved and adjusted with the deepening of future research.

\section{Ackowledgements}

This research was supported by Research Foundation of China University of Petroleum-Beijing at Karamay (RCYJ2017B-03-002) to Q. Zhou.

\section{Conflict of interest}

We all declare that we have no conflict of interest in this paper.

\section{References}

Al Kawasmi, E., Arnautovic, E., \& Svetinovic, D. (2015). Bitcoinbased decentralized carbon emissions trading infrastructure model. Systems Engineering, 18(2), 115-130.

https://doi.org/10.1002/sys.21291

Alkawasmi, E., Arnautovic, E., \& Svetinovic, D. (2012). Requirements model for a high-privacy decentralized carbon emissions trading platform. In IEEE International Conference on Green Computing and Communications (pp. 450-453). IEEE. https://doi.org/10.1109/GreenCom.2012.71

Franke, L., Schletz, M., \& Salomo, S. (2020). Designing a blockchain model for the Paris agreement's carbon market mechanism. Sustainability, 12(3), 1068. https://doi.org/10.3390/su12031068

Fu, B., Shu, Z., \& Liu, X. (2018). Blockchain enhanced emission trading framework in fashion apparel manufacturing industry. Sustainability, 10(4), 1105. https://doi.org/10.3390/su10041105

Green, J., \& Newman, P. (2017). Citizen utilities: The emerging power paradigm. Energy Policy, 105, 283-293. https://doi.org/10.1016/j.enpol.2017.02.004

Hu, D. B., Li, C. F., \& Cai, H. P. (2014). Carbon emission market modeling and simulation based on complex adaptive system theory. Open Cybernetics \& Systemics Journal, 8(1), 11751182. https://doi.org/10.2174/1874110X01408011175

Ilic, D., Da Silva, P. G., Karnouskos, S., \& Griesemer, M. (2012). An energy market for trading electricity in smart grid neighbourhoods. In $6^{\text {th }}$ IEEE International Conference on Digital Ecosystems and Technologies (DEST) (pp. 1-6). IEEE. https://doi.org/10.1109/DEST.2012.6227918 
Kong, C.-Y. (2012). Construction and Simulation of China's carbon emission trading market. Wuyi University.

Lu, J., Song, B., Xiang, W.-H., \& Zhou, Z.-M. (2017). Smart contract for electricity transaction and charge settlement based on blockchain. Computer Systems \& Applications, 26(12), 43-50.

Mengelkamp, E., Gärttner, J., Rock, K., Kessler, S., Orsini, L., \& Weinhardt, C. (2018). Designing microgrid energy markets: A case study: The Brooklyn Microgrid. Applied Energy, 210, 870-880. https://doi.org/10.1016/j.apenergy.2017.06.054

Nakamoto, S. (2008). Bitcoin: A peer-to-peer electronic cash system. Consulted. https://git.dhimmel.com/bitcoin-whitepaper/

National Development and Reform Commission. (2017). National carbon emission trading market construction program (Power Generation Industry) [EB/OL]. https://www.ndrc.gov. cn/xxgk/zcfb/ghxwj/201712/t20171220_960930.html

Pan, Y., Zhang, X., Wang, Y., Yan, J., Zhou, S., Li, G., \& Bao, J. (2019). Application of blockchain in carbon trading. Energy Procedia, 158, 4286-4291.

https://doi.org/10.1016/j.egypro.2019.01.509

Shanghai Development and Reform Commission. (2017). Shanghai carbon emission quota allocation scheme 2017 [EB/OL].

Shanghai Environmental Energy Exchange. (2015). Measures for risk control and management of carbon emission trading in Shanghai environmental energy exchange (Trial Implementation) $[\mathrm{EB} / \mathrm{OL}]$.

Sikorski, J. J., Haughton, J., \& Kraft, M. (2017). Blockchain technology in the chemical industry: Machine-to-machine electricity market. Applied Energy, 195, 234-246.

https://doi.org/10.1016/j.apenergy.2017.03.039
Stranlund, J. K. (2007). The regulatory choice of noncompliance in emission trading programs. Environmental \& Resource Economics, 38(1), 99-117. https://doi.org/10.1007/s10640-006-9058-3

$\mathrm{Wu}$, J.-q. (2015). Carbon emission trading scheme exproation in China and impacts on China's environment and economy: A multi-agent-based model. Beijing University of Chemical Technology.

Wu, Q. (2014). A study on carbon emissions trading market in Shanghai. Shanghai Jiaotong University.

Xie, H., \& Wang, J. (2016). Study on block chain technology and its applications. Journal of Information Security Research, 16(9), 192-195. http://netinfo-security.org/EN/10.3969/j. issn.1671-1122.2016.09.038

Xu, M., \& Tang, W.-W. (2014). Carbon market simulation system based on Java. Computer Systems and Applications, 23(6), $22-27$.

Zeng, G., \& Wan, Z.-h. (2010). Carbon emission trading: A summary of theory and application. Chinese Review of Financial Studies, 2(4), 54-67+124-125.

Zheng, Y.-h. (2016). Research on the pricing mechanism and price operation mechanism of carbon financial market. China University of Mining \& Technology, Beijing.

Zhu, Y. (2016). Security architecture and key technologies of blockchain. Journal of Information Security Research, 2(12), 1090-1097.

http://www.sicris.cn/EN/abstract/abstract199.shtml 